logy), Dr. W. B. Turrill (Botany), Mr. W. F. Okeshott (Education), Prof. H. D. Kay (Agriculture). The Lord Mayor of Birmingham is the local patron, and Sir Raymond Priestley, vice-chancellor of the University of Birmingham, is chairman of the Local Executive Committee. The Lord Mayor of Birmingham has issued an appeal for a local fund of $£ 6,000$, and more than two hundred local volunteers are already making preparations for what is expected to be one of the largest meetings in the history of the British Association. The meeting will be the sixth to be held in Birminghym.

\section{Tribute to Prof. A. Einstein}

In the July issud of the Review of Modern Physics (published September 19), thirty-eight articles written spegienly by well-known physicists from many different countries have been collected together by Dr. W. Pais in commemoration of the seventieth birthday of Prof. Albert Einstein, which occurred on March 14. A recent photograph of Prof. Einstein, showing him sitting at his desk, forms the frontispiece, and in the first four articles, the authors of which are Profs. R. A. Millikan, L. de Broglie (in French), M. von Laue (in German) and Philipp Franck, an appreciation and brief description of Einstein's remarkable contributions to physics and philosophy are given. It is left to these four to convey to Prof. Einstein, for the entire group of authors contributing to the issue, the messages of debt and gratitude which each individually would have liked to express. The theory of relativity, relativistic dynamics, and cosmological applications of relativity are the subjects dealt with in many of the articles; but others are concerned with quite unrelated topics such as turbulence, thermodynamical equilibrium and the transfer-rate of the Rollin-Simon film of liquid helium. From Great Britain there are contributions by Max Born and P. A. M. Dirac ; Canada by L. Infeld and A. Schild; India by H. J. Bhabha; Belgium by G. Lemaître; Holland by A. D. Fokker, J. A. Schouten and W. J. de Haas and G. J. van der Berg; Sweden by O. Klein; Switzerland by W. Pauli and F. Villars; Israel by G. Racah ; Mexico by M. S. Vallarta; and Japan by H. Yukawa. The other contributions are from the United States and include articles by G. Gamow, the late R. C. Tolman, H. P. Robertson, E. P. Wigner, R. Ladenberg ff. von Kármán and O. Stern.

\section{Ocearlography in Germany}

REFERENCE was madelin Nature of September 4 , 1948 (p. 364) to the firs issue of the German hydrographic journal, Deutsthe Hydrographische Zeitschrift. It has now conclughed its first volume with the issue of Nos. 5/6 whichpamong many papers, contains four on purely pedanographical subjects. W. Hansen gives a fu bamental essay on computing tides in ocean aras of any shape by means of the method of boundart values, of which the validity is demonstrat $a^{\circ}$ for the English Channel. K. Kalle describes a handy method of measuring surface currents at sea by producing and following a coloured patch. F. Model compares five hundred reliable observations of surface temperature from almost all Atlantic regions with the average values, and discusses the possibility of a change in climate or of a systematic defect in the earlier method of observing being the cause of systematic discrepancies. O. Pratje, in a geological paper, discusses the variation in sediment type over very limited areas. Of the papers not specifically concerned with oceanography, F. Errulat contributes a chart of the magnetic declination at mid-1945 for the German Bight and the southern Baltic. In a comprehensive article, H. C. Freiesleben discusses position lines (based on terrestrial and wireless bearings as well as on star observations) from a uniform point of view. E. Romer reviews the first seventy years of "German Sailing Directions", and two papers by A. Schluter and J. Nauen deal, theoretically and practically, with the problem of adjusting magnetic compasses and ascertaining their deviation in case of low visibility. Moreover, there is a report on the geomagnetic records at Wingst Observatory in 1942 by $O$. Meyer and a review of S. Chapman's isomagnetic charts by H. G. Macht. The succeeding issue (Vol. 2, Nos. 1/3) will contain several papers read before a geophysical and meteorological meeting held in Hamburg in September 1948.

\section{Royal Commission on Awards to Inventors}

THE Treasury, with the concurrence of the Royal Commission on Awards to Inventors, has issued a notice fixing December 31,1949 , as the final date for the lodging of claims with the Departments. The Royal Conmission on Awards to Inventors under the chairmanship of Lord Justice Cohen was set up by Roygh Warrant in May 1946 to assess the awards to be paid for the use by, or on behalf of, the Crown of inventions, designs, drawings or processes, particularly in connexion with the Second World War. Both the Commission and the Treasury feel that it would be inappropriate for the work of the Commission to be unduly protracted. As more than four years have elapsed since the conclusion of hostilities, the Commission considered that no hardship would be inflicted on inventors if a time limit for the lodgement of claims with the Government Departments were imposed. The expiry of the time limit will in no way deprive a claimant of his right to present a claim in the High Court if his invention is covered by a patent or registered design.

\section{Birmingham Lectures for Research Workers in Industry}

THE University of Birmingham Extra Mural Department, in co-operation with the Departments of Metallurgy and Chemistry, is providing a course of lectures in the new year for research workers in industry. This series of twenty-four lectures, the most ambitious which the University has so far provided extra-murally, commences on January 14, 1950, at the University, Edmund Street. The course was originally conceived by members of the Institute of Physics and the Institute of Metals, and was planned in response to a request made by them to the Extra Mural Department. The course has the general title "Modern Views of the Solid State". An introductory section on the general theoretical background of wave mechanics (F. R. N. Nabarro) leads on to specialized courses dealing with non-metallic solids (J. E. B. Randles) and with metals and alloys (B. A. Bilby). Further details can be obtained from the Director of the Extra Mural Department, University, Edmund Street, Birmingham 3.

\section{Proceedings of the Physical Society: Sections A and B}

ONE of the main reasons for dividing the Proceedings of the Physical Society into two sections A and $\mathrm{B}$ ysas to give the advantage of an increased volumo of publication without burdening the Fellows with a further compulsory increase in subscription; 
this would have been inevitable had an enlarged Proceedings been distributed to all the Fellows. In the light of experience gained over the course of the past year, it has been found that the division which best meets the needs of Fellows is one which brings papers on microphysics and the physics of elementary particles into Section A, and papers on macroscopic physics into Section B. Cases arise where the division is bound to be somewhat arbitrary. While it is essential to maintain a certain amount of flexibility in the allocation of papers, a paper will, so far as possible, be put in the section where the main interest of the readers lies ; for example, a paper on countertechnique would appear in $B$ if the circuitry is the main interest, but would be in $A$ if the applications to actual counting are of major importance. Details are available from the offices of the Physical Society, I Lowther Gardens, Prince Consort Road, London, S.W.7.

\section{University of Glasgow}

THE following annoudefments have recently been made from the Univensity of Glasgow. Prof. W. J. Duncan has bee Elected to the newly founded Mechan chair of heronautics and fluid mechanics. Lecturers heve been appointed as follows: A. C. Crundwe (botany), R. Giles (natural philosophy), A. B Hil (agricultural zoology), S. Mitchell (chemistry to a senior lectureship), B. F. X. Touschek (natural philosophy). Dr. Robert Wright has retired after being senior lecturer in physical chemistry for thirty years. He graduated at the Royal University of Ireland (Queen's College, Belfast), and held an 1851 Exhibition Scholarship during 1912-15 at University College, London, and for the last year at Glasgow, where he was an assistant during 1914-17. After two further years as lecturer at Belfast, Dr. Wright returned to Glasgow in 1919. His research work has been mainly concerned with the study of solutions.

For the present session, 245 students have been newly admitted to the Faculty of Science. This is about ninety fewer than for the previous session, the difference being almost wholly due to the diminution in the number of students from the Forces. About two hundred researeh students have been registered. For the University as a whole, the total of matricylated students is just over 7,000.

\section{University of Cambridge : Appointments}

THE following appointments in the University of Cambridge have been announced: Prof. Dorothy Garrod, head of the Department of Archæology and Anthropology ; S. K. Runcorn, assistant director of research in geophysics; P. Johnson and P. George, assistant directors of research in colloid science. A. G. Brighton has been re-appointed curator of the Sedgwick Museum of Geology, and W. S. Mansfield director of the University farm.

\section{Mineralogical Society: New Officers and Council}

Ax the recent anniversary meeting of the Mineralogical Society, Officers and Council for the session 1949-50 wore elected as follows: President, Prof. C. E. Tiley; Vice-Presidents, Mr. B. W. Anderson and Dr. A. J. Bull; Treasurer, Mr. E. H. Beard; Generdh Secretary, Dr. G. F. Claringbull; Foreign Secretary, Dr. L. J. Spencer; Editor of the Journal, Dr. L. J. Spencer; Ordinary Members of Council, Dr. G. W. Brindley, Dr. F. Dixey, Prof. L. Hawkes, Prof. W. Q. Kennedy, Dr. S. O. Agrell, Mr. H. G.
Dines, Mr. G. S. Gowing, Dr. S. I. Tomkeieff, Dr. F. A. Bannister, D̉r. J. Phemister, Mr. H. M. Powell and Mr. H. P. Rooksby.

\section{Announcements}

Mr. E. V. MurPHreE, president of the Standard Oil Develgpment Co., New York, has been awarded the Perkin Medal by the American section of the Society of Chemical Industry, given annually for outstarding work in applied chemistry. Mr. Murphree is known for his work on synthetic rubber, catalytic cracking, the application of the fluid solids technique, and synthetic liquid fuels.

A SCIEnce Meeting of the Physical Society will be held in the Physics Department University of Birmingham, Adgbaston, Birmingham, on Saturday, December 10, from 9.30 a.m. until 4.30 p.m. The subject of the meeting will be "Nuclear Physics". Talks will be given as follows: in the morning, (i) "Crystals for Scintillation Counters", by G. F. J. Garlick; (ii) "Specul tions about the Origin of the Elements", by Prof. R. E. Peierls ; in the afternoon, (i) "Life-times of Excited Nuclear States", by Mr. D. E. Bunyan; (ii) "The Shell Models of Nuclear Structure", by Dr. J. Lindhard. All physicists interested in the subject are welcome to attend.

IT is announced from Pembroke College, Cambridge, that the Stokes Studentship is about to become vacont. The Studentship will be awarded without distinction of sex; preference will be given to graduates of the University of Cambridge. Candidates must not be less than twenty-three or more than thirty years of age on January 1,1950 , and $a$ preference will be given to those between the ages of twenty-three and twenty-six. They must have shown capacity for research in mathematical or experimental physics or in related subjects, such as physical chemistry or the study of physical laws in relation to living matter. The normal value of the Studentship is $£ 500$ a year for three years. Applicaations must reach the Master of Pembroke College, Cambridge, on or before December 31, 1949, marked on the outside "Stokes Studentship".

To increase production knowledge in industry, the British Welding Research Association has established a team of development and liaison engineers, who will interpret the research results of the Association and discuss the many varied applications of welding with persons and firms interested in such problems. Mr. A. J. Hipperson, who leads the team, was for many years connected with the Welding Advisory Service and has been with the British Welding Research Association since its inception.

A SERIEs of three Christmas Lectures, specially adapted for a juvenile audience of from twelve to seventeen years of age, will be given in the Royal Photogyaphic Society's House, at 16 Princes Gate, London, S.W.7, on December 28, 29 and 30, at 3 p.m. The lecturers and subjects will be as follows: "Photographing People", by Mr. Richard N. Haile; 'How a Photograph Gets into Print", by Mr. F. H. Smith; "Photographing Marine Life", by Dr. Douglas P. Wilson. Admission will be free but by ticket only, obtainable on application to the Secretary of the Society at the above address.

ERratum. In the note in Nature of October 15, p. 649, referring to the journal New Education, the price of the first issue was wrongly given as $1 s .6 d$. This should have been $1 s$. $3 d$. 